\title{
Sinimailasen kasvuunlähtö ja kehitys kylvövuonna sekä talvehtimisen jälkeen
}

\author{
Kirsi Mäkiniemi ${ }^{1)}$, Reija Lesonen ${ }^{2)}$, Markku Niskanen ${ }^{1)}$, Mervi Seppänen ${ }^{3)}$ \\ 1) Luonnonvarakeskus (Luke), Luonnonvarat ja biotuotanto/Tuotantojärjestelmät, Alapääntie 104, 61400 \\ YLISTARO,etunimi.sukunimi@luke.fi \\ 2) Seinäjoen ammattikorkeakoulu (SeAMK), Elintarvike ja maatalous, Ilmajoentie 525, 60800 ILMAJOKI, \\ reija.lesonen@seamk.fi \\ 3) Helsingin yliopisto, Maataloustieteiden laitos, Latokartanonkaari 5, 00014 HELSINGIN YLIOPISTO, \\ mervi.seppanen@helsinki.fi
}

\section{Tiivistelmä}

Sinimailasen kehitys on hidasta perustamisvuonna, jolloin siitä suositellaankin korjaamaan vain yksi sato talvehtimisen varmistamiseksi. Luonnonvarakeskus Ylistaron ja Helsingin yliopiston Talvisopu-hankkeessa selvitetään vuosina 2014 - 2016 sinimailaslajikkeiden (Alexis, Artemis, Lavo, Live ja Nexus) kehitysrytmiä, talvenkestävyyttä, sadontuottoa ja rehulaatua kolmen niiton strategiassa. Tässä artikkelissa selvitetään perustamisvuoden kasvustorakennetta sekä ensimmäisen talven jälkeistä kasvuunlähtöä.

Kasvustot kylvettiin ilman suojakasvia kesäkuun loppupuolella ja kasvuston taimetuttua aloitettiin niiden kehityksen seuranta havainnoimalla pääversojen kehitysastetta sekä sivuversojen muodostumista ja niiden kehitysastetta käyttäen härkäpavulle kehitettyä BBCH-asteikkoa. Kehitykseen vaikuttanutta lämpösummaa alettiin laskemaan kylvöpäivästä alkaen.

Sinimailaslajikkeiden pituuskasvu ja kehitysrytmit erosivat toisistaan vain vähän, ja syksyn puhdistusniittoon mennessä erot olivat tasoittuneet. Kiivain kasvu- ja kehitysvaihe sijoittui välille $500-700$ ${ }^{\circ} \mathrm{Cvrk}$ kylvöstä, minkä jälkeen kasvustot keskittyivät kukintaan. Tässä kokeessa puhdistusniiton aikaista satoa ei mitattu, joten satotasosta ei ole tarkkaa tietoa. Kasvustojen tiheyksien (täystiheät kasvustot) ja pituuksien perusteella satotasojen arvioitiin olevan vähintään noin 2000 - $2500 \mathrm{~kg} \mathrm{ka} / \mathrm{ha}$ luokkaa.

Lajikkeiden pääversojen BBCH-kehitysasteen muutokset eivät eronneet toisistaan. Kasvukausi 2014 oli hyvin lämmin ja lämpösummaa kertyi runsaasti keski- ja loppukesällä, johon kaikki sinimailaslajikkeet reagoivat kukkimalla jo perustamisvuonna. Lajikkeet tuottivat loppukesän aikana keskimäärin kaksi (Alexis ja Artemis) tai kolme (Lavo, Live ja Nexus) sivuversoa, joista osa eteni kehityksessään kukkimisasteelle. Lavolla ja Nexuksella ilmestymisjärjestyksessään kaikki toiset ja kolmannet sivuversot ehtivät kehittyä vähintään korrenkasvuvaiheeseen. Ensimmäisistä sivuversoista osa jäi vegetatiiviselle eli pelkästään lehteä tuottavalle asteelle.

Kasvustojen puhdistusniitto tehtiin pitkään sänkeen (noin $15 \mathrm{~cm}$ ) talvehtimisen varmistamiseksi. Vaikka koelohkolle ei tullut pitkään pysyvää lumipeitettä ja juuristokerros jäätyi talven aikana, kaikki lajikkeet talvehtivat hyvin eikä talvenkestossa tai myöhemmin keväällä havainnoiduissa kevättiheyksissä havaittu eroja. Lajikkeiden välillä ei havaittu selkeitä eroja myöskään kevään kasvuunlähdössä. Sinimailanen aloitti kasvunsa keväällä hyvin aikaisin: kaksi kolmasosaa kasviyksilöistä oli alkanut versoa jo ennen varsinaisen termisen kasvukauden alkua. Sinimailasen talvituhoja ja mahdollisia tuhojen korjaustoimia (jyräys, täydennyskylvö heinillä tai apilalla) tulisikin tarkkailla jo ennen kasvukauden alkua.

Tulosten perusteella suhteellisen myöhään kylvetty sinimailanen voi kukkia myös perustamisvuonna ainakin vuosina, joina loppukesän lämpösummakertymä on korkea. Pitkälle edennyt kehitysaste ennen syksyn niittoa ja versoissa ennen kukintaan siirtymistä havaittu suuri solmulukumäärä saattoi edistää kasvustojen talvehtimista vaativissa olosuhteissa.

\section{Asiasanat}

Sinimailanen, perustamisvuosi, talvehtiminen, kasvuunlähtö 


\section{Johdanto}

Kiinnostus sinimailasen viljelyyn on lisääntynyt Suomessa, vaikka mailaset ovat suhteellisen vaativia viljelykasveja kasvuolojen ja maalajin suhteen. Useimmiten sinimailanen on mukana heinäpitoisissa tai valtaisissa seoksissa ja puhtaat sinimailaskasvustot ovat harvinaisempia. Luonnonvarakeskus Ylistaron ja Helsingin yliopiston Talvisopu-hankkeessa selvitetään vuosina 2014-2016 sinimailaslajikkeiden kehitysrytmiä, talvenkestävyyttä, sadontuottoa ja rehulaatua kolmen niiton strategiassa. Tässä artikkelissa selvitetään perustamisvuoden kasvuston kehitystä, kasvustorakennetta sekä seuraavan kevään kasvuunlähtöä.

\section{Aineisto ja menetelmät}

Luonnonvarakeskus Ylistarossa tutkitaan vuosina 2014 - 2016 sinimailaslajikkeiden talvenkestävyyttä, sadon ja laadun kehitystä sekä näiden yhteyksiä toisiinsa. Koe on perustettu kesällä 2014 neljänä kerranteena ja puhtaina sinimailaskasvustoina viidellä eri lajikkeella: Artemis, Alexis, Nexus, Live ja Lavo. Kylvötiheys oli kaikilla lajikkeilla $700 \mathrm{kpl} / \mathrm{m}^{2}$. Maalajina on multava $\mathrm{HHt}$, jonka $\mathrm{pH}$ on 6,3. Perustamislannoituksessa annettiin väkilannoitteena $30 \mathrm{~kg} \mathrm{~N} / \mathrm{ha}, 3 \mathrm{~kg} \mathrm{P} / \mathrm{ha}$ ja $3 \mathrm{~kg} \mathrm{~K} / \mathrm{ha}$.

Kasvustojen pituuskasvua mitattiin ja versonkehitystä havainnoitiin perustamisvuonna visuaalisin havainnoin. Havaintoja tehtiin sekä koko kasvustosta että yksittäisistä kasviyksilöistä ja niiden pää- ja sivuversoista jokaisessa koeruudussa ( 5 versoa/koeruutu, $n=20 /$ lajike). Kehitysastemääritelmänä käytettiin sinimailasen oman kehitysastekuvauksen puuttuessa härkäpavun BBCH-asteikkoa (Lancashire ym. 1991). Talven jälkeen kasvuunlähtö (kasvunsa aloittaneiden yksilöiden osuus kaikista yksilöistä) havainnoitiin visuaalisesti neljänä ajankohtana kasvukauden käynnistyessä. Lehtialan kehitystä seurattiin viikoittaisilla lehtialaindeksimittauksilla (LAI; LAI-2000 Plant Canopy Analyzer, LI-COR Inc., Lincoln, Nebraska, USA).

Tulokset laskettiin SAS-tilastolaskentaohjelmalla (versio 9.4 ja SAS Enterprise Guide 7.1, SAS Institute Inc., Cary, NC, USA) käyttäen varianssianalyysin sekamallia, jossa lajike oli kiinteä muuttuja, kerranne satunnaismuuttuja ja tilastollisen merkitsevyyden raja p-arvo 0,05. Parivertailuissa käytettiin Tukeyn testiä.

\section{Tulokset ja tulosten tarkastelu}

\section{Kasvustojen kehitys perustamisvuonna}

Ensimmäisellä havaintokerralla $340{ }^{\circ} \mathrm{Cvrk}: n$ kohdalla eli noin kuukauden kuluttua kylvöstä Lavolla ja Nexuksella havaittiin sivuversojen muodostumista (BBCH 28), kun taas muilla lajikkeilla myös päävarren pituuskasvu oli alkanut, Artemiksella (BBCH 32) ja Alexiksella (BBCH 33) kehittymässä oli jo useampi solmuväli (Kuva 1). Hajontojen ollessa suuria ei merkitseviä eroja lajikkeiden kehitysasteiden välillä kuitenkaan havaittu. Pituuskasvun suhteen lajikkeet erosivat toisistaan: Nexus ja Artemis olivat muita lajikkeita lyhyempiä $(p<0,04)$. Noin $500{ }^{\circ} \mathrm{Cvrk}$ :n kohdalla erot lajikkeiden pituuskasvussa olivat hävinneet ja kaikkien lajikkeiden päävarren pituuskasvu oli käynnistynyt. Seuraavan $100{ }^{\circ} \mathrm{C} v r k: n$ aikana kasvustot kehittyivät erittäin nopeassa rytmissä, sillä $600{ }^{\circ} \mathrm{Cvrk}$ :n kohdalla kaikilla lajikkeilla havaittiin vähintään 16 solmuvälin pidentyminen ja Artemiksen nuppujen kehitys oli käynnistymässä (BBCH 50). Keskimääräinen pituuskasvu oli $0,16 \mathrm{~cm} /{ }^{\circ} \mathrm{Cvrk}$, Lavo ja Nexus erottuivat muita lajikkeita hieman lyhyempinä $(p<0,05)$. Nopea kehitys jatkui seuraavan $100{ }^{\circ} \mathrm{Cvrk}$ :n ajan, sillä pituuskasvu säilyi yhtä kiivaana kuin edellisellä havaintovälillä. Lähestyttäessä $700{ }^{\circ} \mathrm{Cvrk}$ :a kaikki lajikkeet olivat edenneet kehityksessään myöhäiselle nuppuasteelle ja Artemiksen kehitysvaihe lähestyi kukinnan alkua. Tämän jälkeen pituuskasvu käytännössä pysähtyi ja noin $800{ }^{\circ} \mathrm{Cvrk}$ :n kohdalla kaikki lajikkeet olivat täyden kukinnan vaiheessa. Kukintavaiheessa Lavon pituus oli lajikkeista pienin $(p=0,03)$.

Syksyn ja talven lähestymiseen reagoivien eli syysdormanssiin siirtyvien sinimailaslajikkeiden versoissa on todettu suurempi solmuvälien ja siten myös solmujen lukumäärä kuin syksyn tuloon reagoimattomien, korkeamman dormanssiluokan lajikkeiden versoissa, joissa puolestaan solmuvälit ovat pidempiä (Liu ym. 2015). Tässä kokeessa kaikkien lajikkeiden solmumäärä oli suuri eikä niissä havaittu eroja lajikkeiden välillä, mikä saattaa viitata lajikkeiden samankaltaiseen, voimakkaaseen dormanssitaipumukseen ja siten hyvään talvenkestoon.

Tulosten perusteella sinimailaslajikkeiden pituuskasvu ja kehitysrytmit erosivat toisistaan vain vähän, ja syksyn puhdistusniittoon mennessä erot olivat tasoittuneet. Kiivain kasvu- ja kehitysvaihe sijoittui välille $500-700{ }^{\circ} \mathrm{Cvrk}$ kylvöstä, minkä jälkeen kasvustot kehittyivät kukintavaiheeseen ja pituuskasvu lähes loppui. 
Tässä kokeessa puhdistusniiton aikaista satoa ei mitattu, joten satotasosta ei ole tarkkaa tietoa. Kasvustojen tiheyksien (täystiheät kasvustot) ja pituuksien perusteella satotasojen arvioitiin olevan vähintään samaa tasoa tai jonkin verran korkeampia kuin kokeen vuoden 2015 kolmannessa niitossa (Mäkiniemi ym. 2016), eli noin 2000 - $2500 \mathrm{~kg}$ ka/ha luokkaa, mikä on täysin mahdollista Suomen kasvuoloissa (Vuorinen \& Takala, 1993).
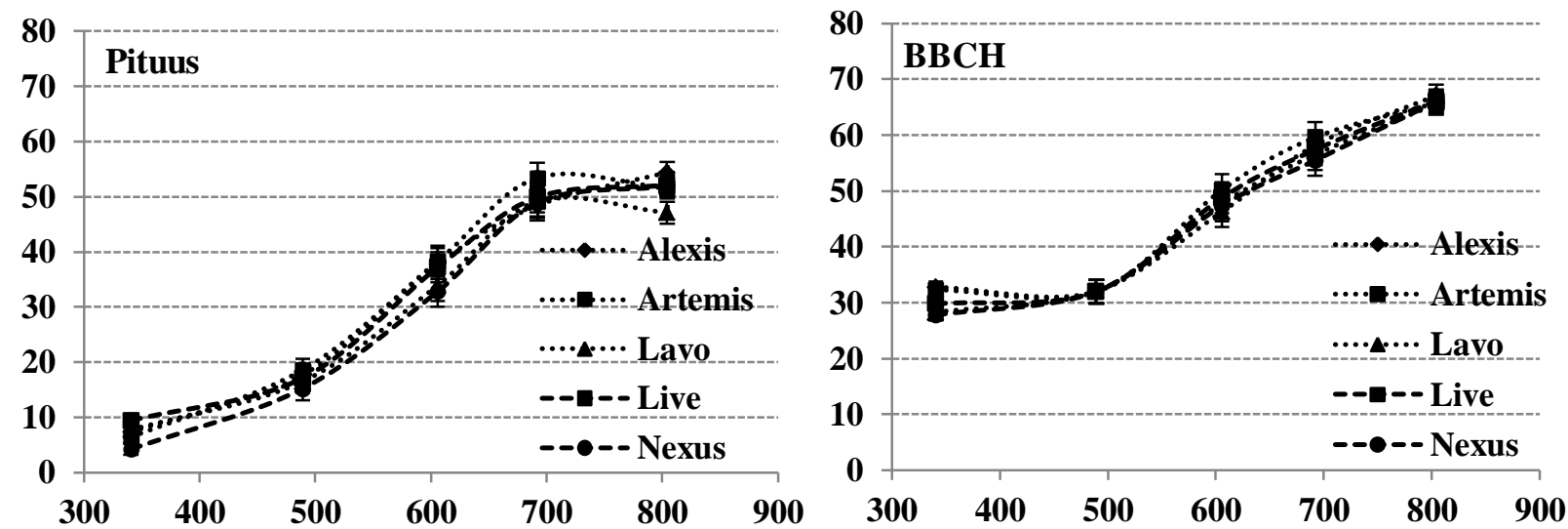

Kuva 1. Sinimailaslajikkeiden kasvuunlähtö (pituus ja kehitysaste $B B C H$-asteikolla) perustamisvuoden kesällä ja syksyllä 2014 Luke Ylistarossa.

\section{Pääversojen ja sivuversojen kehitys perustamisvuonna}

Sinimailaslajikkeista havainnoitiin pääversojen ja sivuversojen kehitystä. Kasvukausi 2014 oli hyvin lämmin ja lämpösummaa kertyi runsaasti keski- ja loppukesällä, johon kaikki sinimailaslajikkeet reagoivat kukkimalla jo perustamisvuonna (Kuva 2; generatiiviset versot, BBCH 50-69).
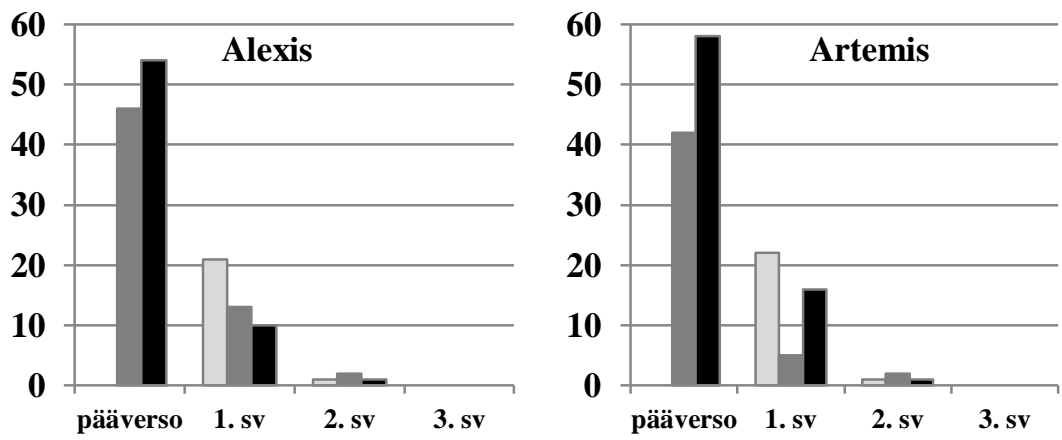

$$
\begin{aligned}
& \square \text { vegetatiiviset (10 - 29) } \\
& \square \text { elongoituvat (30 - 39) } \\
& \square \text { generatiiviset (50 - 69) }
\end{aligned}
$$
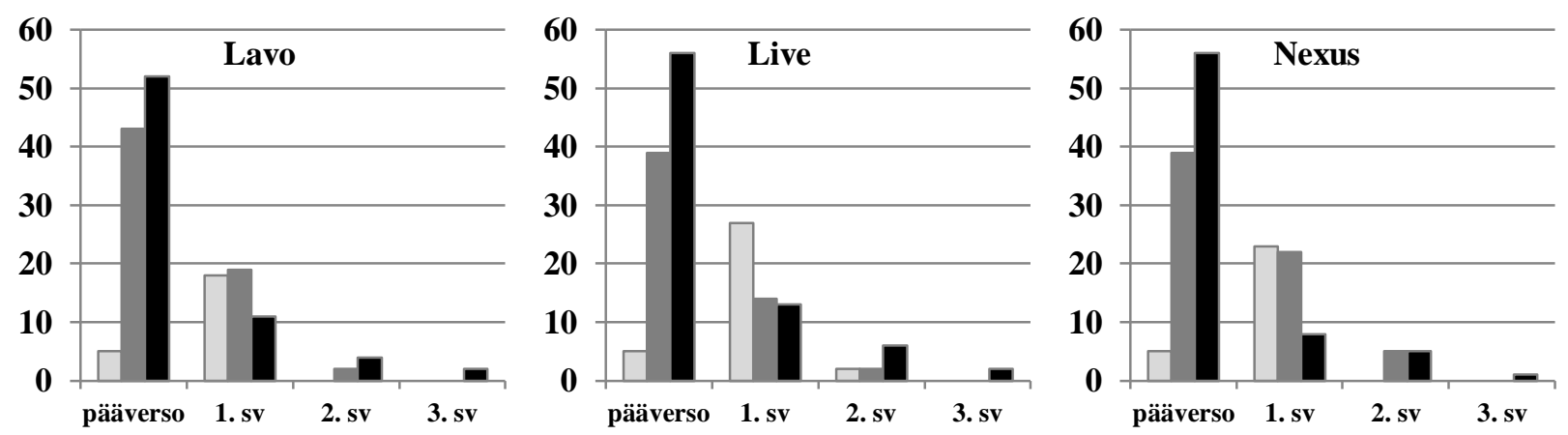

Kuva 2. Sinimailaslajikkeiden pääversojen ja kolmen ensimmäisen sivuverson eri versotyypit kasvukauden 2014 havaintohetkinä (tarkastelussa versot summattu yli havaintokertojen). Versot on jaoteltu versotyyppeihin kehitysasteensa perusteella seuraavasti: vegetatiivinen: $\mathrm{BBCH} 10$ - 29; elongoituva: $\mathrm{BBCH} 30$ - 39; generatiivinen: BBCH $50-69$. 
Lajikkeiden pääversojen $\mathrm{BBCH}-k e h i t y s a s t e e n$ muutokset eivät eronneet toisistaan. Vegetatiivisia (BBCH 10-29; Kuva 2) eli pelkkää lehteä tuottavia pääversoja oli $340{ }^{\circ} \mathrm{Cvrk}: n$ kohdalla muilla lajikkeilla paitsi Alexiksella ja Artemiksella. Kasviyksilöihin kehittyi perustamisvuonna enimmillään kolme sivuversoa (Kuva 2). Lajikkeet tuottivat loppukesän aikana keskimäärin kaksi (Alexis ja Artemis) tai kolme (Lavo, Live ja Nexus) sivuversoa, joista osa eteni kehityksessään generatiiviselle eli kukkimisasteelle. Lavolla ja Nexuksella ilmestymisjärjestyksessään kaikki toiset ja kolmannet sivuversot ehtivät kehittyä aitoon korrenkasvuvaiheeseen, jostaa versot mahdollisesti vielä etenevät kukintaan (elongoituvat; BBCH 30-39; Kuva 2). Ensimmäisistä sivuversoista osa jäi vegetatiiviselle asteelle.

Versohavaintoja tehtiin kuitenkin sen verran vähän, ettei varsinaisia eroja lajikkeiden välillä pystytty osoittamaan. Pää- ja sivuversohavaintojen perusteella sinimailasen perustamisvuoden kehitys on enimmäkseen pääverson kehitystä, mutta sivuversot saattavat hyödyttää kasvia täyttämällä muutoin hieman aukkoiseksi jäävää kasvustoa. Tämän saman kenttäkokeen ensimmäisenä varsinaisena satovuonna (kasvukausi 2015) sivuversojen muodostus oli selvästi perustamisvuotta runsaampaa, sillä kaikilla lajikkeilla havaittiin vähintään 7 sivuversoa, innokkaimmalla versojalla Livellä jopa 11 sivuversoa (Mäkiniemi ym., julkaisematon).

\section{Kasvustojen kasvuunlähtö keväällä talven jälkeen}

Kevään kasvuunlähdön havainnot tehtiin neljänä kertana siihen saakka, kunnes riittävä peittävyyden taso saavutettiin ja lehtialaindeksimittaukset pystyttiin aloittamaan. Ensimmäinen havainnointipäivä oli 16.4.2015, jolloin tehoisaa lämpösummaa ei ollut vielä kertynyt (Taulukko 1), mutta keskimäärin $65 \%$ kasvustoista oli nähtävissä elonmerkkejä. Ensimmäiset kolme havaintokertaa sijoittuivat kahden viikon ajalle, mutta koska kasvukauden alku eteni hyvin hitaasti eikä tehoisaa lämpösummaa juuri kertynyt, edistyi kasvuunlähtö hyvin hitaasti. Neljännellä havaintokerralla toukokuun alkupuolella lämpösumman kehitys oli paremmin vauhdissa ja kaikkien lajikkeiden peittävyys koeruuduissa oli jo lähes $90 \%$. Samaan aikaan myös kasvuston peittävyys alkoi olla tasainen ja lehtialaindeksi (LAI) ylitti arvon 1 (Kuva 3). LAI-arvot kohosivat ensimmäisen sadon kehittyessä nopeasti ja suhteellisen tasaisesti $150-200{ }^{\circ} \mathrm{Cvrk}$ tienoille. Lajikkeet eivät eronneet toisistaan lehtialan kehityksen suhteen.

Lajikkeiden välillä ei havaittu selkeitä eroja kasvuunlähdössä tai talvenkestävyydessä ensimmäisen talven jälkeen. Sinimailanen aloitti kasvunsa keväällä hyvin aikaisin: kaksi kolmasosaa kasviyksilöistä oli alkanut versoa jo ennen varsinaisen termisen kasvukauden alkua (Taulukko 1). Sinimailasen talvituhoja ja mahdollisia tuhojen korjaustoimia (jyräys, täydennyskylvö heinillä tai apilalla) tulisikin tarkkailla jo ennen kasvukauden alkua.

Taulukko 1. Sinimailas lajikkeiden kas vuunlähtö (kasvunsa aloittaneiden yksilöiden osuus kaikista yksilöis tä) visuaalisesti arvioituna keväällä 2015 talven jälkeen Luke Ylis tarossa. Lajikkeiden välillä ei ollut tilastollis esti merkitseviä eroja.

\begin{tabular}{crrrr} 
Kas vuun- & \multicolumn{4}{c}{ Päivämäärä } \\
\cline { 2 - 5 } lähtö $(\%)$ & $\mathbf{1 6 . 4 . 2 0 1 5}$ & $\mathbf{2 4 . 4 . 2 0 1 5}$ & $\mathbf{2 8 . 4 . 2 0 1 5}$ & $\mathbf{9 . 5 . 2 0 1 5}$ \\
\hline${ }^{\mathbf{0} C v r k}$ & $\mathbf{0 , 0}$ & $\mathbf{4 , 7}$ & $\mathbf{6 , 7}$ & $\mathbf{4 1 , 4}$ \\
\hline Alexis & $72 \mathrm{a}$ & $78 \mathrm{a}$ & $83 \mathrm{a}$ & $91 \mathrm{a}$ \\
Artemis & $53 \mathrm{a}$ & $64 \mathrm{a}$ & $68 \mathrm{a}$ & $86 \mathrm{a}$ \\
Lavo & $70 \mathrm{a}$ & $71 \mathrm{a}$ & $75 \mathrm{a}$ & $92 \mathrm{a}$ \\
Live & $61 \mathrm{a}$ & $59 \mathrm{a}$ & $66 \mathrm{a}$ & $84 \mathrm{a}$ \\
Nexus & $68 \mathrm{a}$ & $69 \mathrm{a}$ & $78 \mathrm{a}$ & $91 \mathrm{a}$ \\
\hline keskiarvo & $\mathbf{6 5}$ & $\mathbf{6 8}$ & $\mathbf{7 4}$ & $\mathbf{8 8}$ \\
SEM & 14,1 & 13,4 & 13,4 & 5,6 \\
$p$-arvo & \multicolumn{5}{|}{0,79} & 0,7 \\
$p$-arvo & 0,83 & 0,8 & 0,79
\end{tabular}




\section{Johtopäätökset}

Sinimailasten kehitys oli hidasta perustamisvuonna, eivätkä alkuperältään erilaisten sinimailaslajikkeiden pituuskasvu, kehitysrytmi tai pää- ja sivuversonta juuri eronneet kylvövuonna toisistaan. Kiivain kasvu- ja kehitysvaihe sijoittui välille $500-700^{\circ} \mathrm{C}$ vrk kylvöstä, minkä jälkeen kasvustot kukkivat. Tässä kokeessa puhdistusniiton aikaista satoa ei mitattu, joten satotasosta ei ole tarkkaa tietoa.

Kaikki viisi lajiketta talvehtivat hyvin eikä talvenkestossa tai myöhemmin keväällä havainnoiduissa kevättiheyksissä havaittu eroja. Pitkälle edennyt kehitysaste ennen syksyn niittoa ja versoissa ennen kukintaan siirtymistä havaittu suuri solmulukumäärä saattoi edistää kasvustojen talvehtimista vaativissa olosuhteissa. Lajikkeiden välillä ei havaittu selkeitä eroja myöskään kevään kasvuunlähdössä. Sinimailanen aloitti kasvunsa keväällä jo ennen varsinaisen termisen kasvukauden alkua, mikä viittaa siihen, että sinimailasen mahdollisia talvituhoja ja niiden korjaustoimia (jyräys, täydennyskylvö heinillä tai apilalla) tulisikin tarkkailla jo ennen kasvukauden alkua.

\section{Kirjallisuus}

Fick, G.W. \& Mueller, S.C. 1989. Alfalfa: Quality, maturity, and mean stage of development. Department of Agronomy, College of Agriculture and Life Sciences, Cornell University. Information Bulletin 217

Lancashire, P.D., Bleiholder, H., Langeluddecke, P., Stauss, R., van den Boom, T., Weber, E. \& Witzen-Berger, A. 1991. A uniform decimal code for growth stages of crops and weeds. Ann. Appl. Biol. 119 (3): 561-601.

Liu, Z., Li, X., Wang, Z. \& Sun, Q. 2015. Contrasting Strategies of Alfalfa Stem Elongation in Response to Fall Dormancy in Early Growth Stage: The Tradeoff between Internode Length and Internode Number. PLoS ONE 10(8).

Mäkiniemi, K., Javanainen, J., Lappalainen, H., Niskanen, M. \& Seppänen, M. 2016 (in press). Puhdas sinimailaskasvusto tulee niittää ajoissa. Teoksessa: Maataloustieteen Päivät, 12.-13.1.2016. Suomen maataloustieteellisen seuran tiedote: $6 \mathrm{~s}$.

Peltonen, J. 1995. Kasvuasteet viljelytoimien tarkkaan ajoitukseen, Käytännön Maamies 7/1995, s.25-38.

Vuorinen, M. \& Takala, M. 1993. Sinimailasen viljelyyn vaikuttavia tekijöitä. Maatalouden tutkimuskeskus, Tiedote 16/93: $17 \mathrm{~s}$. 